\title{
ANÁLISE DAS VARIÁVEIS CONTINGENCIAIS NA GESTÃO DE CUSTOS DA CADEIA DE VALOR DE UMA INDÚSTRIA DE PAPEL E CELULOSE
}

\author{
Marcio Roberto Piccoli ${ }^{1}$ \\ Leandro Augusto Toigo ${ }^{2}$ \\ Fabricia Silva da Rosa ${ }^{3}$
}

RESUMO: A presente pesquisa tem como objetivo analisar a influência das variáveis contingenciais na gestão de custos da cadeia de valor de uma indústria de celulose pela percepção dos seus gestores. Para isso, realizou-se uma pesquisa descritiva, qualitativa, estudo de caso, com a aplicação de entrevista semiestruturada com executivo de uma empresa de Papel e Celulose que atua na região meio-oeste de Santa Catarina. Para complementar a entrevista foram utilizados relatórios financeiros, societários, de sustentabilidade, e outros, disponíveis no sítio da BM \& FBovespa. Utilizando a técnica de análise de conteúdo, os dados obtidos da entrevista e dos relatórios publicados foram analisados. Como resultados encontrados constatou-se que a cadeia de valor da empresa é fortemente verticalizada e identificaram-se também as variáveis internas e externas que oferecem aumentos ou reduções de custos na cadeia de valor e consequentemente nos produtos finais da empresa. Conclui-se pelo estudo que a empresa necessita de constantes investimentos em tecnologia para o sucesso de se sua cadeia de valor e que está focada em atender as necessidades dos seus clientes e monitora constantemente a cadeia de valor buscando aplicar práticas de redução de custos que atendam também as necessidades dos clientes da companhia, que é produtora de papel para embalagens industriais.

Palavras-chave: Variáveis contingenciais. Gestão estratégica de custos. Cadeia de valor.

\footnotetext{
${ }^{1}$ Mestre em Ciências Contábeis pela Fundação Regional de Blumenau - FURB, Professor da Área de Ciências Sociais Aplicadas da UNOESC, Campus de Joaçaba. Contador Público. Santa Catarina. Brasil. E-mail: marcio.piccoli@unoesc.edu.br

${ }^{2}$ Doutorando do Programa de Pós-Graduação em Ciências Contábeis e Administração Centro de Ciências Sociais Aplicadas Fundação Universidade Regional de Blumenau - FURB. Santa Catarina. Brasil. E-mail: leandrotoigo@yahoo.com.br

${ }^{3}$ Professora do Programa de Pós-Graduação em Ciências Contábeis e Administração Centro de Ciências Sociais Aplicadas Fundação Universidade Regional de Blumenau - FURB. Santa Catarina. Brasil. E-mail: fabriciasrosa@hotmail.com
} 


\title{
CONTINGENCY VARIABLES ANALYSIS ON COST MANAGEMENT OF SUPPLY CHAIN IN THE PULP AND PAPER FACTORY
}

\begin{abstract}
This paper seeks to analyze the influence of contingency variables in the cost management of the supply chain of a paper and pulp factory according of the CEO viewpoint. Thus, the classified research in descriptive, qualitative, case with the application of semi-structured interview with the CEO of Pulp and Paper factory which operates in the midwestern region of Santa Catarina state. To complement the interview financial reporting, corporate, sustainability, and others, available on the BM\&FBovespa page were used. Using the technique of content analysis, the data obtained from interviews and published reports were analyzed. As results it was found that the supply chain of the company is strongly vertical and also identified the internal and external variables that offer cost reductions or increases in the supply chain and consequently the final products of the company. It was concluded by the study that the company needs constant investment in technology for the success of their supply chain and is focused on meeting the needs of its customers and constantly monitors the supply chain seeking to implement practices that meet cost reduction also the needs of customers of the company, which is a producer of industrial packaging paper
\end{abstract}

Keywords: Contingency variables. Strategic cost management. Supply chain.

\section{INTRODUÇÃO}

O advento da competitividade global acelerada, reduzidos ciclos de produtos, rápidos avanços tecnológicos, organizacionais e entre cadeias, tem aumentado drasticamente a necessidade de abordagens mais eficazes de gestão dos custos (LOCKAMY III, 2003). A importância de toda a cadeia de valor deve ser entendida no contexto de uma cadeia global e o gerenciamento de custos eficaz exige um foco externo à empresa (SHANK; GOVINDARAJAN, 1997).

Para Shank e Govindarajam (1997) a Gestão Estratégica de Custos surge para atender as necessidades de adaptação das organizações a um contexto de busca por melhoria contínua da competitividade. Nesse sentido, Camacho e Rocha (2007) abordam que a cadeia de valor é ampla e possibilita a busca por produtos similares e negociação com fornecedores. Para os autores, a indústria modifica facilmente seus produtos a partir das novas tecnologias, substituição de componentes e reestruturação de processos. 
A cadeia de valor de uma empresa tem uma forte interação com os fornecedores, os quais influenciam na redução de custos dos componentes utilizados (BRITO; GARCIA; MORGAN, 2008).

Alguns autores afirmam que os custos podem ser utilizados no desenvolvimento de estratégias e vantagem competitiva sustentável, dos quais citam-se: Porter (1989), Shank; Govindarajan (1997), Cooper; Slagmulder (1998), Aguiar; Rocha (2007), Rocha (1999), Lockamy III (2003), Anand (2004), Anderson (2006), Ellram (2006), Souza; Rocha (2008), Wrubel (2009) e Wrubel et al. (2011).

Para Bornia e Lorandi (2011) a cadeia de valor está relacionada com a qualidade exigida pelo consumidor final. Sendo assim, para que se busque atender os objetivos, não se podem visualizar apenas as operações internas, isoladamente, embora isso seja útil para integrar todas as funções, atividades e tarefas (BOWERSOX; CLOSS, 1996). Neste sentido ocorre a influência dos fatores contingenciais na cadeia de valor. Para Espejo (2008, p. 16) "fatores contingenciais são variáveis que influenciam a condução organizacional". Woodward (1965); Waterhouse e Tiessen (1978); e Fisher (1995) contribuem postulando que não existe um SCG único para todos os tipos de empresas, sendo que o mesmo é moldado pela influência dos fatores contingenciais.

Com base nestes autores parte-se para o pressuposto que as variáveis contingenciais influenciam nas práticas de gestão de custos e condução organizacional, portanto não se obteria um modelo único. Diante disso e mantendo o foco no tema a solução encontrada foi a realização da pesquisa em um tipo específico de indústria. As indústrias do setor de papel e celulose possuem uma cadeia de valor complexa, abrangendo as etapas de formação das florestas, processamento da madeira, fabricação de celulose, conversão de papel em artefatos, produção gráfica, produção editorial e reciclagem do papel utilizado (LOPES, 1998). O Brasil está entre os quatro produtores mundiais de celulose (BRACELPA, 2012), e está abrindo seus mercados cada vez mais, tornando-se mais suscetível a competição estrangeira (BAER, 2009). Nesse sentido, o mercado tornou-se mais competitivo, ainda que substancialmente mais concentrado, já que as empresas ficaram mais vulneráveis à entrada e à rivalidade de competidores potenciais, o que pôde inibir possível exercício de poder de mercado das empresas. O mesmo autor destaca ainda que "do ponto de vista da política econômica, o que 
realmente conta é se as condições aparentemente mais contestáveis dos mercados nos últimos anos foram associadas com melhoras no desempenho competitivo, seja este medido por produtividade, custo unitário ou inovação" (p. 502).

Após a abordagem do Sistema de Controle Gerencial e do meio para sua concretização, que é a Gestão de custos na cadeia de valor, acrescentando breve exposição das indústrias de celulose, propôs-se o seguinte problema de pesquisa: Qual a influência das variáveis contingenciais para a gestão de custos na cadeia de valor de uma companhia de papel e celulose do Brasil? O objetivo geral deste estudo é analisar a influência das variáveis contingenciais na gestão de custos na cadeia de valor de uma empresa que atua no setor de papel e celulose, sendo que a abordagem foi realizada por meio de entrevista semiestruturada de um dos gestores do controle gerencial da indústria, juntamente com o apoio da utilização de relatórios financeiros, societários, de sustentabilidade, e outros, divulgados no sítio da BM\&FBOVESPA.

O estudo justifica-se pois se torna um mapeamento atualizado das condicionantes ambientais externas e internas a empresa que possam influenciar em aumentos ou reduções dos custos de produção. Portanto, a ótica proporcionada pela cadeia de valor oferece uma visão ampliada da gestão e controle dos custos de todo o negócio da empresa respeitando o seu posicionamento estratégico.

\section{FUNDAMENTAÇÃO TEÓRICA}

Para dar sustentação teórica à pesquisa, esse tópico aborda $A$ teoria contingencial, seus pressupostos e suas variáveis já consolidadas na literatura, as quais serão investigadas. Aborda-se ainda, a importância da gestão estratégica de custos e a cadeia de valor, importantes para as decisões estratégicas sustentáveis de uma organização. Também se discute os pontos mais importantes sobre a cadeia de valor e suas contribuições, e por fim, realizou-se breve explanação de alguns estudos relacionados. 


\subsection{TEORIA CONTINGENCIAL}

As organizações empresariais têm como principal objetivo a sua continuidade, e nesse sentido o estudo da estrutura organizacional é fator preponderante para que isso se concretize. Por meio dos estudos de Woodward (1965); Waterhouse e Tiessen (1978); e Fisher (1995), considera-se que a teoria da contingência postula a visão de que não existe sistema de controle universal que atenda a todas as organizações, são as circunstâncias ou o contexto enfrentados pelas organizações que determinam quais sistemas de controle são apropriados. A teoria da contingência baseia-se na premissa da existência de um modelo de contabilidade gerencial e consequentemente de custos, que se adaptem as empresas em todas as circunstâncias (MOLINARI; GUERREIRO, 2004).

$\mathrm{Na}$ aplicação da teoria da contingência na contabilidade gerencial, tem-se que não existe um sistema único de controle de gestão, mas sim a escolha de técnicas adotadas diante das circunstâncias que a organização está inserida (SILVA et al. 2012), tudo é relativo; portanto, não existe o modelo de decisão que seja aplicável indistintamente a toda e qualquer organização (ESPEJO, 2008).

Nesse sentido, Covaleski, Dirsmith e Samuel (1996) afirmam que as contingências influenciam a estrutura das organizações. "Uma contingência é algo que não pode ser influenciado pela organização, porém é capaz de influenciar a organização" (MOLINARI; GUERREIRO, 2004).

Para Luft e Shields (2003) a teoria da contingência é fonte de muitas das variáveis não contábeis, tais como tamanho da organização, incerteza ambiental, tecnologia. Os autores complementam que nas empresas, a teoria contingencial assume a tendência a usar a contabilidade gerencial da melhor maneira que lhes favoreça e o que deve ser considerado é a combinação de fatores, que ajustados indicariam a decisão a ser tomada.

Junqueira (2010) complementa que as variáveis contingenciais que exercem influência nas organizações podem ser tanto variáveis internas (exemplos: estrutura ou tamanho), como variáveis externas (exemplos: globalização ou avanço tecnológico). Para Espejo (2008) variáveis externas são aquelas denominadas ambientais, também consideradas por Chenhall (2003) como sendo atributos particulares como intensa competição de preço de competidores potenciais ou 
existentes, ou a probabilidade de uma mudança na disponibilidade de materiais. Já as variáveis internas se referem a decisões controláveis pela empresa, tais como escolhas tecnológicas, estrutura, estratégia e porte (ESPEJO, 2008).

Percebe-se que a teoria contingencial é bastante usada quando nos referimos a contabilidade gerencial, com a finalidade de melhorar o controle das organizações. Tem-se ainda, que essa abordagem contingencial também é aplicada em estudos envolvendo especificamente o gerenciamento de custos, proporcionando maior eficiência da estrutura empresarial.

Estudos como os de Dekker e Smidt (2003) mostraram que fatores contingenciais como um ambiente imprevisível e a concorrência intensa estão relacionados ao uso da técnica do custeio alvo. Por outro lado, o número de concorrentes não teve relação com a teoria abordada.

Estudo mais recente envolvendo custos e a teoria contingencial, foi realizado por Marques (2012) a qual observou que a partir dos fatores contingenciais analisados (incerteza, concorrência, estratégia, porte, estrutura e tecnologia) ambos favorecem a utilização da técnica do custeio alvo, que para os autores essa prática gerencial é compatível com estratégias empresariais conservadoras.

Nota-se pelos achados dos autores, que o uso das variáveis contingenciais não fornece resultados semelhantes. Para a teoria contingencial não há nada que seja absoluto (DONALDSON, 2001), tudo é relativo, não existindo um modelo de decisão aplicável a toda e qualquer organização (ESPEJO, 2008).

Para Rocha e Martins (1999) a gestão de custos pode ser influenciada pelo lucro em virtude de ser uma garantia de sobrevivência e pela competição. Para o autor a ideia de competição quer dizer que há certa discussão sobre os custos antes de haver qualquer produção e é nesse contexto que a variável contingencial externa (competitividade) exerce sua influência no gerenciamento e obtenção do custo meta, a partir do preço formado pelo mercado.

Nesse sentido, acredita-se que para se ter sucesso na gestão dos custos em uma estrutura adequada, se faz necessário adequar-se aos fatores contingenciais, e assim ao ambiente onde se está inserido (DONALDSON, 2001). É a combinação de variáveis contingenciais que conduzirão a organização a um desempenho superior (DRAZIN; VAN DE VEN, 1985). 
Busca-se dessa forma aplicar as variáveis contingenciais observadas, no contexto do segmento de papel e celulose do Brasil, a fim de analisar sua influência quanto a gestão de custos e a cadeia de valor como um todo, proporcionando com isso uma visão mais aprofundada desse segmento de mercado brasileiro.

\subsection{GESTÃO ESTRATÉGICA DE CUSTOS}

As organizações estão suscetíveis a constantes mudanças impostas por seus ambientes internos e externos, e que o Sistema de Controle Gerencial - SCG pode auxiliar o gestor na formulação da melhor estratégia competitiva para seu negócio, pela dinâmica do ambiente empresarial é necessário constante monitoramento das variáveis contingenciais, e isso é perfeitamente executável por um SCG (CHENHALL, 2003).

Em um contexto avançado, os sistemas de custeio tradicionais apresentam limitações por limitam-se apenas ao ambiente interno da empresa sem levar em consideração, por exemplo, a globalização e o ambiente tecnológico. A gestão estratégica de custos vem preencher essa lacuna deixada pelos sistemas tradicionais, analisando toda cadeia de valor, desde a aquisição de matérias primas até a preocupação com o consumidor final, fazendo com isso seja analisado e gerenciado em bases históricas, compreendendo todo o funcionamento da cadeia de valor.

A gestão estratégica de custos deve buscar uma constante minimização dos custos na fase de projetos e de estudos. Dessa forma, a gestão tem por objetivo igualar o custo projetado ao custo real, envolvendo todos os participes ou agentes do processo de uma cadeia de valor, criando alternativas econômicas para que o projeto seja sustentável e rentável, ou seja, que atenda ao estabelecido e proposto por um custo meta.

Diante das constantes mudanças de mercado e de economia, as empresas buscam constantemente maximizar suas vantagens competitivas, e a gestão estratégica faz parte desse processo, articulando as qualidades e habilidades empresariais às vantagens competitivas de mercado largando à frente de seus concorrentes quando um plano de alcance de resultados estiver bem definido. 
Sob essa perspectiva de gerenciamento, tem-se a contabilidade gerencial responsável por medir e reportar as informações financeiras e não financeiras que ajudam os gestores a tomar decisões, para atingir os objetivos da organização (HORNGREN; FOSTER; DATAR, 2000). Para Anthony e Govindarajan (2002) a gestão de uma organização exige informações relevantes para o processo decisório.

Como parte integrante do Sistema de controle gerencial, o tema gestão estratégica de custos (GEC), considerado por Shank e Govindarajan (1997) é "uma análise de custos, vista sob um contexto mais amplo, em que os elementos estratégicos tornam-se mais conscientes, explícitos e formais", sendo foco de discussões que geraram relevantes estudos.

Bacic (1994) assevera que a gestão estratégica de custos tem como premissa, apoiar a competitividade da empresa, sob o olhar de análise e atuação de um horizonte de longo prazo e no reconhecimento de que o importante não é a gestão dos custos atuais e sim a gestão dos recursos que propiciarão os ganhos futuros. Corroborando desse pensamento, Hansen e Mowen (2001, p. 423) afirmam que a gestão estratégica de custos "é o uso de custos para desenvolver e identificar estratégias superiores que produzirão uma vantagem competitiva".

Para Shank e Govindarajan (1997) custeio baseado em atividades, análise de cadeia de valor, custos da qualidade e direcionadores de custos, são algumas das práticas de gestão estratégica de custos, capazes de fazer a diferença em um ambiente competitivo.

Monden (1999, p. 27) define gestão estratégica de custos como "um sistema de administração por toda a empresa que apoia o processo de custo-alvo" o qual é definido por Hansen e Mowen (2001, p. 443) pela "diferença entre o preço de venda necessário para se capturar uma fatia predeterminada de mercado e o lucro desejado por unidade".

Apresentam-se ainda os estudos de Ellram; Siferd (1993) que tratam sobre o custo total de propriedade, Faria e Costa (2005) custos logísticos, Ellram (2006) sobre custo-meta.

Para os autores da presente pesquisa, a gestão estratégica de custos tem como foco ampliar o horizonte de atuação da organização, fazendo com que o olhar sobre custos não seja somente interno e presente, mas tem por objetivo proporcionar a adoção de uma plano capaz de otimizar resultados aumentando a 
competitividade e lucratividade da organização a partir da utilização de ferramentas de controle gerencial.

Para Frezatti et al. (2012) embora os sistemas de controle gerencial devam estar presentes em todas as empresas, tem-se que com o passar do tempo, a revisão dos sistemas principalmente em momentos de mudanças na empresa. Para Jordão e Souza (2012, p. 58) "O SCG pode ser visto como um mecanismo facilitador da implementação de estratégias corporativas e um dos principais componentes de gestão".

O sistema de gestão de custos da empresa deve ser mais dinâmico para lidar com a mais rápida mudança no ambiente e com a crescente diversidade de produtos e processos de fabricação (EL KELETY, 2006). Por esse motivo, destaca-se a importância de toda a cadeia de valor, podendo afirmar que toda a empresa deve ser entendida no contexto de uma cadeia global e o gerenciamento de custos eficaz exige um foco externo à empresa (SHANK, 1995).

Nesse viés, de gerenciamento e controle, Hansen (2002, p. 14), citado por Bomfim (2006) define custeio alvo dentro de uma gestão estratégica de custos como:

[...] um processo de planejamento de resultado, com base no gerenciamento de resultado de custos e preços que se fundamenta em preços de venda estabelecidos pelo mercado e nas margens objetivadas pela empresa. Nesse processo, os custos são definidos na fase de projeto de novos produtos, visando a satisfação dos clientes e otimizando o custo de propriedade do consumidor, abrangendo toda a estrutura organizacional da empresa e todo o ciclo de vida do produto, envolvendo um segmento relevante da cadeia de valor.

A partir da conceituação proposta por Hansen (2002) considerando que o mercado de papel e celulose no Brasil está em franca expansão, sendo a quarta geradora de papel e celulose do mundo e por sermos um país emergente abrindo e competindo em mercados internacionais, o custeio alvo dentro de uma gestão estratégica de custos é fundamental para o atingimento das margens da empresa bem como o fortalecimento e manutenção do ciclo de vida de um produto.

A relação da gestão de custos com cadeia de valor pode ser identifica a partir da conceituação de Rocha (1999, p. 126) o qual define custo alvo como o montante de custos a ser eliminado ou aumentado para que o custo estimado se ajuste ao permitido, tendo como uma das bases cada elo da cadeia de valor. Ampliando o 
pensamento de Rocha (1999), Bornia e Lorandi (2011) apresentam o gerenciamento de custos interorganizacionais, ou seja, é quando compradores e fornecedores tornam-se eficientes em suas interfaces da cadeia de valor, primeiro reduzindo os custos de processamento e em segundo as incertezas pelo incremento de informações compartilhadas, reduzindo o tempo do ciclo de um produto.

$\mathrm{Na}$ cadeia de valor, os atores: fornecedores, revendedores e pessoal de suporte e serviço, são partes do processo de custeio alvo, ajudando a focar o esforço de redução de custos através de toda cadeia (BORNIA; LORANDI, 2011) sendo este (custeio alvo) utilizado como principal ferramenta na gestão do custo da cadeia de suprimentos (COOPER; SLAGMULDER, 1998).

A GEC, é a "aplicação das técnicas de gestão de custos de maneira que, simultaneamente, melhore a posição estratégica de uma empresa e reduza seus custos" (COOPER; SLAGMULDER, 1998, p. 14). Dessa forma, a fim de atender seus objetivos, a Gestão Estratégica de Custos se baseia, de acordo com Shank e Govindarajan (1997, p. 8), em três abordagens: "(1) Análise da cadeia de valor; (2) Análise do posicionamento estratégico; (3) Análise dos direcionadores de custos". Com o propósito de não fugir do foco do estudo será abordado unicamente a análise da cadeia de valor.

\subsection{ANÁLISE DA CADEIA DE VALOR}

Para que se consiga implantar as estratégias pela empresa, é necessário analisar a cadeia de valor, a qual envolve desde fornecedores e clientes, ou seja, o fluxo total das atividades desenvolvidas pela organização. Nesse sentido, o estrategista deve estudar os envolvidos, para entender como os produtos devem ser desenvolvidos e por fim utilizados (PORTER, 1989).

A definição de cadeia de valor para Porter (1989) está focada em gerenciar custos com enfoque amplo. Para Porter (1989, p. 44) A cadeia de valor é "um sistema de atividades interdependentes. As atividades de valor estão relacionadas por meio de elos dentro da cadeia de valor". A empresa como um todo "é uma reunião de atividades que são executadas para projetar, produzir, comercializar, entregar e sustentar seu produto" (PORTER, 1989, p. 31). 
Utilizando-se de um conceito mais abrangente, ampliado de Porter (1989) por Shank e Govindarajan (1997, p.14) "a cadeia de valor para qualquer empresa, em qualquer negócio, é o conjunto interligado de todas as atividades que criam valor, desde uma fonte básica de matérias-primas, passando por fornecedores de compradores, até a entrega do produto final às mãos do consumidor".

Já para Rocha e Borinelli (2007) o conceito apresentado por Shank e Govindarajan (1997) incorreu em dois erros graves, ou seja, ao considerarem matéria-prima os autores deixaram de observar a cadeia de valor no segmento de serviços e o segundo erro apontado, refere-se à entrega final às mãos do consumidor, caracterizando não haver mais nada a ser feito após a venda.

Com base nessa discussão, Rocha e Borinelli (2007, p.149) concluem que a cadeia em uma empresa pode ser definida como "uma sequência de atividades que se inicia com as origens de recursos e vai até o descarte do produto pelo último consumidor". Para os autores essa definição abarca todos os recursos envolvidos em uma cadeia de valor, bem como o descarte pelo último consumidor, haja vista, que em muitas vezes um produto pode passar de consumidor para consumidor até ser destruído.

O conceito de cadeia de valor deve ser entendido diferente do conceito de valor agregado bastante utilizado pela contabilidade, em que se inicia pelas compras e se encerra nas vendas, maximizando a diferença entre estes. A cadeia de valor procura explorar as ligações com fornecedores e demais agentes da empresa, considerados muito importantes para esta, sendo a cadeia de valor responsável pela maximização das oportunidades de mercado e gerenciamento dos custos envolvidos.

Pode-se dessa forma afirmar, que a cadeia de valor é otimizada à medida que seus elos convergem para um mesmo lugar, havendo maior interdependência dos agentes, ou seja, o fornecedor não deve somente atender ao seu cliente, mas sim dar-lhe condições, ser flexível a fim de atender às exigências da melhor forma esse cliente final. Dessa maneira o ganho não é somente do fornecedor, mas de todos na cadeia, em função do reflexo da inovação gerada no mercado. "De nada adianta lançar um novo produto se a Cadeia de Suprimentos não tiver condições de fabricálo a um custo compatível com o que o mercado está disposto a pagar" (BORNIA; LORANDI, 2011). 
A análise da cadeia de valor constitui-se em uma ação relevante para a tomada de decisões na gestão estratégica, pois leva em considerações variáveis contingenciais, que por sua vez, representam mudanças nos custos operacionais das empresas. Para Porter (1989) e Shank e Govindarajan (1997) deve-se atentar para a seguinte situação: os fornecedores não produzem e entregam apenas insumos que serão utilizados nas atividades de valor de uma empresa, mas influenciam de modo importante os custos e posição de custos/diferenciação da empresa.

Hofer, De Souza e Robles Junior (2007) concluíram em seu estudo que a análise da cadeia de valor possui enfoque amplo, externo e pode influenciar no gerenciamento estratégico dos custos, tendo em vista a sua ligação conjunta nas atividades geradoras de valor em toda linha, desde as matérias-primas básicas até o consumidor final. Para os Autores, o posicionamento estratégico da empresa pesquisada para concorrer no mercado, pode ser definido através da liderança de custos/diferenciação.

A cadeia de valor permite que a firma conheça como se estrutura o processo de formação do valor do bem ou serviço que ela vende, como se agrega valor no processo e como isso é percebido pelo cliente final, quais são as suas relações de mercado com outros agentes econômicos (como fornecedores de matéria-prima ou de equipamentos) e quais seriam os fatores que poderiam alterar o custo ao longo da cadeia (DA SILVA; KOPITTKE, 2002). Cada agente atuante de uma cadeia de valor deve conduzir seus planos estratégicos sem prejuízo aos demais elos da cadeia, pois a concorrência deve ser com outras cadeias e não com os componentes dela própria (ROCHA; BORINELLI, 2007).

Para Rocha (1999) a cadeia de valor fornece subsídios para o processo como um todo e tem por objetivos detectar oportunidades e ameaças, detectar oportunidades de diferenciação, identificar os determinantes de custos, localizar oportunidades de redução de custos e comparar-se a cadeia de valor dos concorrentes. Para Rocha e Borinelli (2007) é partir desses objetivos, que a cadeia de valor age sobre a estrutura econômica, financeira e patrimonial da empresa conquistando e mantendo vantagem competitiva.

Para Wood Jr. e Caldas (2007) mercado, configuração industrial e concorrência são fatores estruturais determinantes de competitividade, os quais 
estão bem desenvolvidos nos setores de papel e celulose e siderurgia. Para os autores um dos problemas em setores menos desenvolvidos é a reduzida articulação em sua cadeia de valor.

Para obter maior vantagem competitiva no setor de papel e celulose, um dos pontos analisados por Da Silva e Kopittke (2002) são a verticalização da cadeia produtiva e consolidação patrimonial; reflorestamentos; desenvolvimento de fibras; escala de produção e capacitação tecnológica. Para os autores é dessa forma que as empresas do setor continuarão concorrendo com o mercado mundial.

Quando a empresa participa de diversas etapas da cadeia de valor ela é denominada verticalmente integrada (SHANK; GOVINDARAJAN, 1997). Quanto à definição de integração vertical, Rocha (2002, p. 5) afirma que "integração vertical implica uma organização produtiva na qual uma única firma é responsável por duas etapas interligadas do processo de fabricação de um bem qualquer".

No caso de empresas papel e celulose, a integração vertical funciona como uma forma de fomentar a produção em grande escala e as plantas fabris, disponibilizando aos produtores florestais, insumos, assistência técnica e capacitação. Em uma estrutura de cadeia de valor de uma empresa de papel e celulose a principal agregação de valor se origina do fornecimento de celulose e tecnologia na exploração da madeira, tornando as firmas mais integradas na busca por uma maior competitividade (DA SILVA; KOPITTKE, 2002).

\subsection{CADEIA DE VALOR DO SETOR DE PAPEL E CELULOSE E ESTUDOS RELACIONADOS}

A cadeia de valor da indústria de papel e celulose demonstra um grau de complexidade produtiva, que necessita de altos investimentos. Carvalho (2001) a partir de seu estudo sobre os custos ambientais na cadeia de papel e celulose define de forma simplificada o fluxo produtivo dessa atividade, conforme Figura 1. 
Figura 1: Cadeia de valor Papel e Celulose

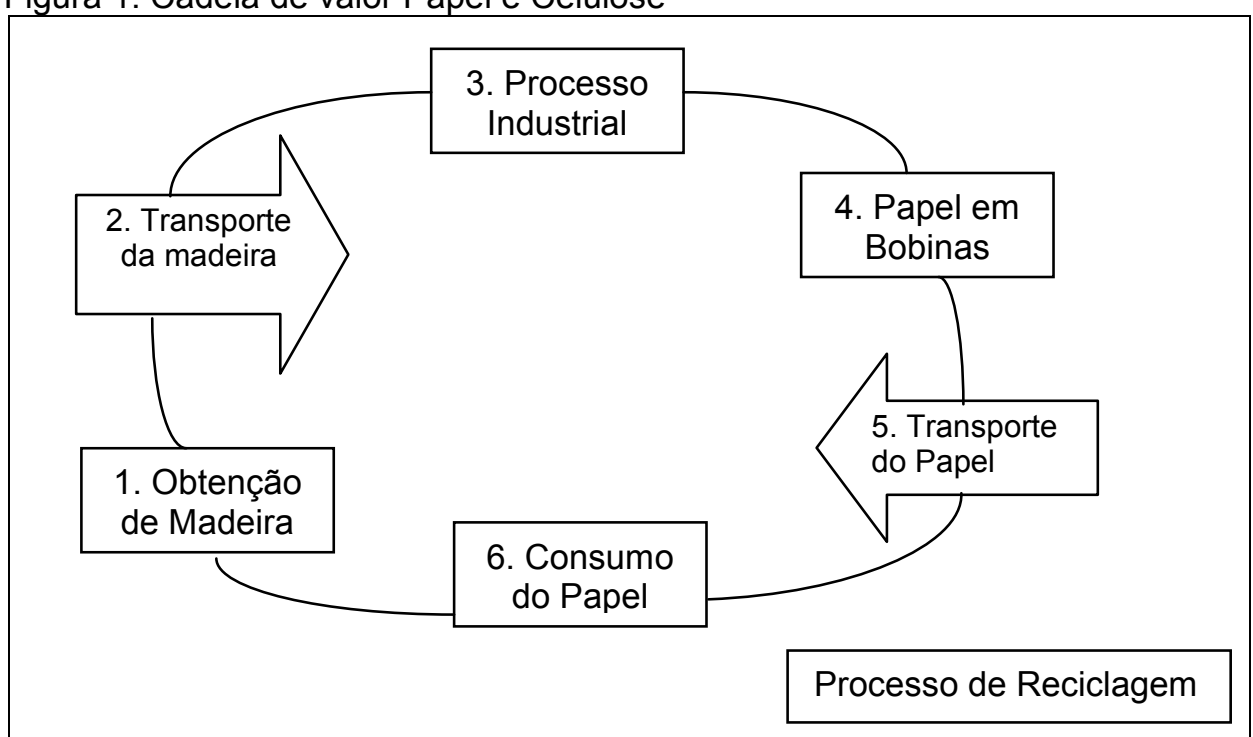

Fonte: Adaptado de Carvalho (2001).

Nota-se, pela Figura 1, que a cadeia de valor da celulose possui várias etapas externas e a cadeia de valor interna não foi demonstrada pelo estudo de Carvalho (2001). Shank e Govindarajan (1997, p. 65) citam algumas atividades estratégicas da cadeia de valor da indústria de produtos de papel: "Transporte e Corte da Madeira, Fabricação da Polpa, Fabricação do Papel, Operações de Transformação, Distribuição". Conforme abordado anteriormente por Shank e Govindarajan (1997), normalmente a cadeia de valor da indústria de papel e celulose apresenta-se verticalizada, sendo que isso pode ser constantemente revisado, pois segundo Porter (1989), a empresa realiza estudos sobre a questão de comprar componentes em vez de fabricá-los ou contratar uma assistência técnica em vez de organizá-la internamente.

A partir da literatura abordada, apresentam-se alguns estudos relacionados à cadeia de valor e as contingências. Espejo (2008) utilizando a abordagem contingencial buscou compreender os atributos do sistema orçamentário considerando níveis de desempenho, de forma que a composição e razões de seu uso (como forma de comunicação das metas, avaliando desempenho, sendo um instrumento de planejamento operacional e de formação da estratégia) parecem estar relacionadas às variáveis contingenciais que afetam a empresa: incerteza ambiental percebida, a estratégia em foco, a estrutura organizacional, a tecnologia empregada em seu sistema de informação e o seu porte. 
A partir de um estudo na Seara Alimentos S/A Gallon, Grunow e Beuren (2009) analisaram a cadeia de valor e dos custos das rações pesquisando as etapas do ciclo produtivo e os custos das rações ao longo da cadeia de valor da produção de aves. Os autores concluíram que o conhecimento da cadeia de valor é elemento relevante no custo total e favorece a busca por melhorias no resultado global da cadeia.

O estudo de Junqueira (2010) a partir da ótica da teoria contingencial examinou os efeitos diretos e interativos dos fatores contingenciais internos estratégia, estrutura, tecnologia da informação e estágio do ciclo de vida organizacional - e do ambiente no perfil do SCG. Os resultados mostraram que ao separar grupos distintos de empresas (indústria, comércio e serviços) foi aceita a hipótese de associação entre fator contingencial e ambiente.

Marques (2012) utilizou a teoria contingencial para investigar e identificar a influencia do uso dessa teoria sobre o custeio alvo. Utilizando-se de uma pesquisa documental e entrevista semiestruturada, com análise qualitativa de conteúdo, o autor concluiu que os fatores contingenciais favorecem a utilização do custeio alvo, principalmente no que se refere a variável tecnologia.

Dias Jordão e De Souza (2013) examinaram a aquisição de empresas sob a ótica da teoria contingencial, tendo como objetivo, examinar quais as mudanças no Sistema de Controle Gerencial de uma empresa após sua incorporação por outra. A partir da aplicação de questionário de 38 questões, aplicado a pessoas de diferentes cargos níveis, os autores tiveram como conclusões de que uma estratégia corporativa tem influência direta no crescimento lucrativo e sustentável dos negócios. Quanto à abordagem contingencial, percebeu-se que essa teoria é uma abordagem de suporte para análise de mudanças no Sistema de Controle Gerencial pós-aquisições, embora para os autores ainda os estudos sejam escassos.

Estudos sobre o setor de papel e celulose foram abordados por Da Silva e Kopittke (2002) os quais aplicaram algumas simulações de cenários no setor de papel e celulose a partir da cadeia de valor. Os autores tiveram como resultados que a cadeia de valor pode ser um importante instrumento gerencial para apoiar a tomada de decisão, reduzindo parte das incertezas em riscos.

Analisando as práticas de gestão de pessoas em uma cadeia de clientes, fornecedores e concorrentes de uma empresa de papel e celulose a partir da teoria 
institucional, Lacombe e Chu (2008) concluíram que além da estratégia organizacional, fatores institucionais podem ser determinantes para a elaboração das políticas de gestão de pessoas, evidenciando assim ser vantajosa a inclusão da abordagem institucional nos estudos desse campo. Para os autores as políticas e práticas da gestão de pessoas são produtos da conciliação das influências de diversos fatores, dentre os quais a estratégia organizacional.

Borges, Rosa e Ensslin (2010) pesquisaram a evidenciação voluntária das práticas ambientais das empresas do setor de papel e celulose, observaram que na grande maioria das empresas pesquisadas as políticas ambientais estão amplamente evidenciadas. Por outro lado, aspectos financeiros e ambientais são apresentados em caráter descritivo. Os autores apontam que por ser uma prática voluntária, não sendo possível afirmar a veracidades das informações, sugerem a necessidade e a obrigatoriedade de auditoria nos relatórios anais de sustentabilidade, assim como o realizado nas demonstrações contábeis.

Percebe-se pelas pesquisas realizadas apresentadas, que estudos no setor de papel e celulose brasileiro envolvendo teoria contingencial e cadeia de valor ainda são escassos. Nesse sentido, nosso estudo apresenta-se como lacuna de pesquisa, corroborando com as demais já realizadas investigar a cadeia de valor sob a ótica das variáveis contingenciais, as quais bastante debatidas em estudos de contabilidade trazendo importantes resultados para essa ciência, principalmente quando relacionada a contabilidade gerencial, ramo da contabilidade importante na gestão estratégica de custos das empresas.

\section{METODOLOGIA}

Quanto aos objetivos, a pesquisa caracteriza-se como descritiva, qualitativa com desenvolvimento de estudo de caso. Como universo populacional definiram-se as empresas do setor econômico de papel e celulose. Considerando que o objetivo deste estudo está relacionado à cadeia de valor, gestão de custos e variáveis contingenciais, busca-se em um estudo de caso aprofundar a investigação com o propósito de se encontrar grandes achados.

A empresa objeto de estudo é uma companhia aberta que atua no setor desde 1941, quando foi fundada, é a terceira maior empresa no setor de papel e 
celulose que produz especificamente embalagens de papel para indústrias alimentícias. Possui aproximadamente 2 mil funcionários, faturamento estimado para 2013 de 900 milhões. Atua com produção de papel e celulose, com florestas próprias, num total de 30 mil hectares plantados em um raio médio de $25 \mathrm{~km}$ em torno da fábrica que está situada na região meio-oeste do estado de Santa Catarina.

Para a coleta de dados foi desenvolvido um roteiro de entrevista semiestruturada com questões elaboradas com base nas variáveis contingenciais utilizadas nos estudos de Espejo (2008) e Junqueira (2010), buscando identificar a percepção dos respondentes de cada etapa da cadeia interna de valor sobre a interferência dessas variáveis na execução dos processos da cadeia: (a) externo: ambiente; (b) interno (decisões controláveis): tecnologia, estrutura, estratégia e porte, conforme Quadro 1.

Quadro 1 - Descrição das variáveis utilizadas no estudo

\begin{tabular}{|c|c|c|c|c|}
\hline & VARIÁVEL & $\begin{array}{l}\text { AUTOR(ES) } \\
\text { (ANO) }\end{array}$ & DESCRIÇÃO & $\begin{array}{c}\text { NO } \\
\text { ESTUDO }\end{array}$ \\
\hline 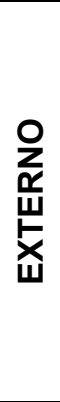 & Ambiente & $\begin{array}{l}\text { Gordon; } \\
\text { Narayanan (1984); } \\
\text { Sharma (2002) e } \\
\text { Hansen e Van der } \\
\text { Stede (2004) }\end{array}$ & $\begin{array}{l}\text { Abrangem características de estabilidade, } \\
\text { previsibilidade e a rapidez de mudanças } \\
\text { com relação a (a) atitudes da concorrência; } \\
\text { (b) competição por mão de obra; (c) } \\
\text { competição por compra de } \\
\text { insumos/componentes; (d) tecnologia } \\
\text { aplicada ao processo produtivo; (e) } \\
\text { restrições legais, políticas e econômicas do } \\
\text { setor; e (f) gostos e preferências dos clientes } \\
\text { do setor. }\end{array}$ & $\begin{array}{l}\text { Similar, } \\
\text { com foco no } \\
\text { produto de } \\
\text { cada elo da } \\
\text { cadeia } \\
\text { interna. }\end{array}$ \\
\hline \multirow{3}{*}{$\begin{array}{l}\text { OO } \\
\text { 品 } \\
\text { 点 } \\
\underline{Z}\end{array}$} & Tecnologia & $\begin{array}{l}\text { Dekker, Groot e } \\
\text { Shoute }(2007, \text { p. } \\
46)\end{array}$ & $\begin{array}{l}\text { Indicadores da tecnologia aplicada ao } \\
\text { processo produtivo referem-se a: (a) o grau } \\
\text { de repetitividade das atividades da linha de } \\
\text { produção, (b) quantas tarefas da linha de } \\
\text { produção são as mesmas dia após dia; (c) } \\
\text { quantas pessoas fazem tarefas } \\
\text { diversificadas a maioria do tempo na linha } \\
\text { de produção da empresa. }\end{array}$ & $\begin{array}{l}\text { Similar, } \\
\text { com foco no } \\
\text { produto de } \\
\text { cada elo da } \\
\text { cadeia } \\
\text { interna. }\end{array}$ \\
\hline & Estrutura & $\begin{array}{l}\text { Gordon, } \\
\text { Narayanan (1984) } \\
\text { e Sharma (2002). }\end{array}$ & $\begin{array}{l}\text { Grau de descentralização. A delegação de } \\
\text { autoridade analisada com base nos } \\
\text { seguintes aspectos: (a) com relação ao } \\
\text { desenvolvimento de novos produtos; (b) } \\
\text { contratação e demissão de pessoal; (c) } \\
\text { seleção de investimentos considerados } \\
\text { relevantes para a empresa; (d) alocação } \\
\text { orçamentária e (e) decisão de preços. }\end{array}$ & $\begin{array}{l}\text { Similar, } \\
\text { com foco no } \\
\text { produto de } \\
\text { cada elo da } \\
\text { cadeia } \\
\text { interna. }\end{array}$ \\
\hline & Estratégia & $\begin{array}{l}\text { Porter (1989); } \\
\text { Hansen e Van der } \\
\text { Stede (2004); } \\
\text { Gordon e } \\
\text { Narayanan (1984). }\end{array}$ & $\begin{array}{l}\text { Custos ou diferenciação, enfoque (PORTER, } \\
\text { 1989). Itens abordados para investigação } \\
\text { das empresas são as seguintes: (a) ênfase } \\
\text { na busca da alta qualidade do } \\
\text { produto/serviço, muito maior do que a da } \\
\text { concorrência; (b) oferecer suporte ao cliente } \\
\text { do produto/serviço; (c) desenvolver }\end{array}$ & $\begin{array}{l}\text { Similar, } \\
\text { com foco } \\
\text { em cada elo } \\
\text { da cadeia } \\
\text { de valor } \\
\text { interna. }\end{array}$ \\
\hline
\end{tabular}

Ágora: R. Divulg. Cient., v. 21, n. 1, p. 84-120, jan./jun. 2016 (ISSNe 2237-9010) 


\begin{tabular}{|l|l|l|l|}
\hline & & $\begin{array}{l}\text { características únicas do produto/serviço; (d) } \\
\text { buscar uma imagem da marca muito melhor } \\
\text { do que a da concorrência; (e) investir em } \\
\text { Pesquisa e Desenvolvimento muito mais do } \\
\text { que a concorrência e, por fim (f) buscar um } \\
\text { preço de venda muito menor do que o da } \\
\text { concorrência. }\end{array}$ & \\
\hline \multirow{2}{*}{ Porte } & $\begin{array}{l}\text { Merchant (1984); } \\
\text { Hansen e Van der } \\
\text { Stede (2004) e } \\
\text { SEBRAE }\end{array}$ & $\begin{array}{l}\text { Número de funcionários; funcionários em } \\
\text { tempo integral na empresa. }\end{array}$ & $\begin{array}{l}\text { Quantidade } \\
\text { de } \\
\text { produção } \\
\text { papel e } \\
\text { celulose }\end{array}$ \\
\hline
\end{tabular}

Fonte: Elaborado pelos autores.

Por meio do Quadro 1, são apresentada as variáveis contingenciais que serviram de base para a elaboração do roteiro semiestruturado que foi aplicado a um Executivo da Companhia. Tal Executivo foi definido por acessibilidade e significativos conhecimentos em contabilidade de custos e finanças. O entrevistado atualmente, ocupa o cargo de Coordenador financeiro, trabalha na empresa há 9 anos e a 2 no último cargo, possui pós-graduação, e está com 34 anos.

A entrevista foi realizada e devidamente gravada no dia 14 de dezembro de 2013. Por meio da técnica de análise de conteúdo dos transcritos e gravação foi construída a análise dos dados, para complementar a pesquisa, foram utilizados também relatórios divulgados no sítio da BM\&FBOVESPA, tais como: relatórios financeiros, societários, de sustentabilidade, e outros.

Com tal subsídio foi inicialmente mapeada a cadeia de valor completa, com seus elos interno e externos a empresa, envolvendo fornecedores, clientes e o processo produtivo interno. Logo depois foram identificadas as variáveis contingenciais que possivelmente poderiam estar impactando na gestão de custos da organização.

\section{RESULTADOS}

Esta seção relata os achados sobre a influência das variáveis contingenciais na gestão de custos da cadeia de valor da empresa. Inicialmente foi realizada breve apresentação do ambiente da empresa, também foi mapeada a cadeia de valor, logo em seguida, foram apresentadas as considerações do entrevistado, segundo sua percepção sobre o tema. 


\subsection{AMBIENTE DE NEGÓCIO DA EMPRESA}

Por meio da entrevista e o do relatório de sustentabilidade publicado no sítio da BM\&FBovespa foi obtido um breve relato da abrangência da empresa. A empresa de grande porte possui florestas próprias 100\% renováveis e por questões estratégicas compra de terceiros $30 \%$ da produção para fomentar estes parceiros para uma possível ampliação de fábrica ou por algum problema que ocorra nas florestas próprias. A empresa produz e desenvolve as próprias mudas plantadas, juntamente com a preparação do solo, plantio e manutenção da floresta. As mudas são desenvolvidas pela empresa em parceria com a Empresa Brasileira de Pesquisas Agropecuárias (EMBRAPA) e são certificadas pelo Forest Stewardship Council (FSC), que possibilitou à empresa de papel e celulose o desenvolvimento de novos clientes. Os produtos vendidos pela empresa são basicamente caixas de papelão, sacos, pacotes e bobinas de papel pardo para alguns parceiros, sendo que seus produtos são vendidos basicamente para grandes indústrias alimentícias.

\subsection{MAPEAMENTO DA CADEIA DE VALOR}

O mapeamento da cadeia de valor é um exercício importante para este estudo, pois fornece uma base concreta para análise das variáveis contingenciais externas e internas na gestão de custos. Mapeando a cadeia de valor da companhia, possibilita a percepção da atuação da empresas com seus fornecedores, clientes, consumidores, etc., ou seja, todos os seus elos da cadeia de valor. No Quadro 2 são descritos os elos de forma detalhada obtidos por meio da entrevista e relatórios internos e próprios da empresa. 
Análise das variáveis contingenciais na gestão de custos da cadeia de valor de uma indústria de papel e celulose

Quadro 2 - Elos da cadeia de valor

\section{$1^{\circ}$ ELO DA CADEIA - VIVEIRO DE MUDAS}

O primeiro elo da cadeia de valor da celulose é o viveiro de mudas que é composta pelo Pinheiro Americano (pinus elliottii). A empresa industrializa unicamente este tipo de planta, pois atua na produção de celulose para fabricação de embalagens. No Brasil esta cultivar apresenta a vantagem competitiva de ser colhida após 14 anos do plantio, enquanto que em outros países como no norte da Europa demora até 40 anos para ser cortado

\section{$2^{\circ}$ ELO DA CADEIA - PLANTIO DAS FLORESTAS}

Nesta fase as mudas são transplantadas em grandes áreas de terra da própria empresa e depois de 14 anos tornam-se florestas prontas para o corte.

$3^{0}$ ELO DA CADEIA - CORTE DAS TORAS DA FLORESTA

Nesta etapa as toras prontas são cortadas por equipe de trabalhadores terceirizados por meio de outra empresa que fornece o serviço. Por estas características esta etapa pode ser considerada como um elo externo da cadeia de valor.

$4^{\circ}$ ELO DA CADEIA - TRANSPORTE DAS TORAS

O transporte é realizado por meio de frota de caminhões terceirizado. Os veículos possuem carrocerias e reboques específicos para o transporte de toras, não podendo carregar outro tipo de carga. Esta etapa também é considerado um elo externo da cadeia de valor.

5 ELO DA CADEIA - COZIMENTO

A fábrica recebe as toras que entram no processo de cozimento, que é feito por meio de um digestor que dissocia das toras a lignina (elemento aglutinante das fibras da madeira) das fibras celulósicas.

$6^{0}$ ELO DA CADEIA - DEPURAÇÃO

O produto final desta etapa é uma massa que é a celulose industrial, sendo que neste processo são eliminadas todas as sujeiras e rejeitos vindos da etapa cozimento.

$7^{\circ}$ ELO DA CADEIA - DESAGREGAÇÃO

A celulose chega em solução aquosa com consistência de 3\% a 6\% sendo submetida a uma ação mecânica que transforma folha seca em concentração adequada.

$8^{\circ}$ ELO DA CADEIA - REFINO E ADITIVOS

Nesta etapa ocorre a inclusão de aditivos como sulfato de alumínio, que transfere energia para as fibras, quanto maior for o processo de refino melhores serão as propriedades da celulose.

$9^{\circ}$ ELO DA CADEIA - FORMAÇÃO DE FOLHAS

A massa de celulose é espalhada em uma caixa com o fundo de tela composta por tecido sintético e malha onde que é removida parte da água, assim, são formadas as primeiras lâminas de papel.

$10^{\circ}$ ELO DA CADEIA - PRENSAGEM

Tendo as lâminas de papel formadas ocorre o processo de prensagem e pré-secagem. O processo dará forma ao papel e aumentará a concentração de celulose com o processo de secagem. Aplica-se à folha um filme superficial para melhorar a qualidade de impressão, esta aplicação ocorre por meio de prensa e cola.

$11^{\circ}$ ELO DA CADEIA - SECAGEM

Nesta etapa o ocorre a secagem do papel, sendo que o produto final para sair deste processo necessita atingir alguns requisitos mínimos de qualidade, tais como: gramatura, umidade, tonalidade, alvura e teor de cinza.

\section{$12^{\circ}$ ELO DA CADEIA - ENROLAMENTO}

Neste processo as folhas de papel adquirem mais qualidade por meio de calandras, que é um conjunto de rolos superpostos que tornam a superfície do papel mais lisa a acetinada.

$13^{\circ}$ ELO DA CADEIA - BOBINAMENTO

Nesta etapa as folhas são enroladas em grandes bobinas.

$14^{\circ}$ ELO DA CADEIA - CORTE E ACABAMENTO DAS EMBALAGENS

Nesta etapa as bobinas são desenroladas e juntamente com a lâmina de aparas são montadas as lâminas sanduíche para caixa de papelão. Logo em seguida, elas recebem impressão e corte específicos solicitados pelos clientes.

Fonte: Dados da pesquisa

Ágora: R. Divulg. Cient., v. 21, n. 1, p. 84-120, jan./jun. 2016 (ISSNe 2237-9010) 
Percebe-se pelo Quadro 2, cada elo da cadeia de valor ou etapa do processo produtivo da empresa. Em cada etapa são utilizados equipamentos de alta tecnologia para que seja mantida a qualidade e o baixo custo dos produtos. Nota-se também que os elo 3 e 4 são os únicos elos externos da empresa. Com base no Quadro 2 foi elaborado a Figura 2 que evidencia os elos da cadeia de valor da companhia, obtida por meio da descrição do entrevistado.

Figura 2 - Cadeia de valor da indústria de papel e celulose.

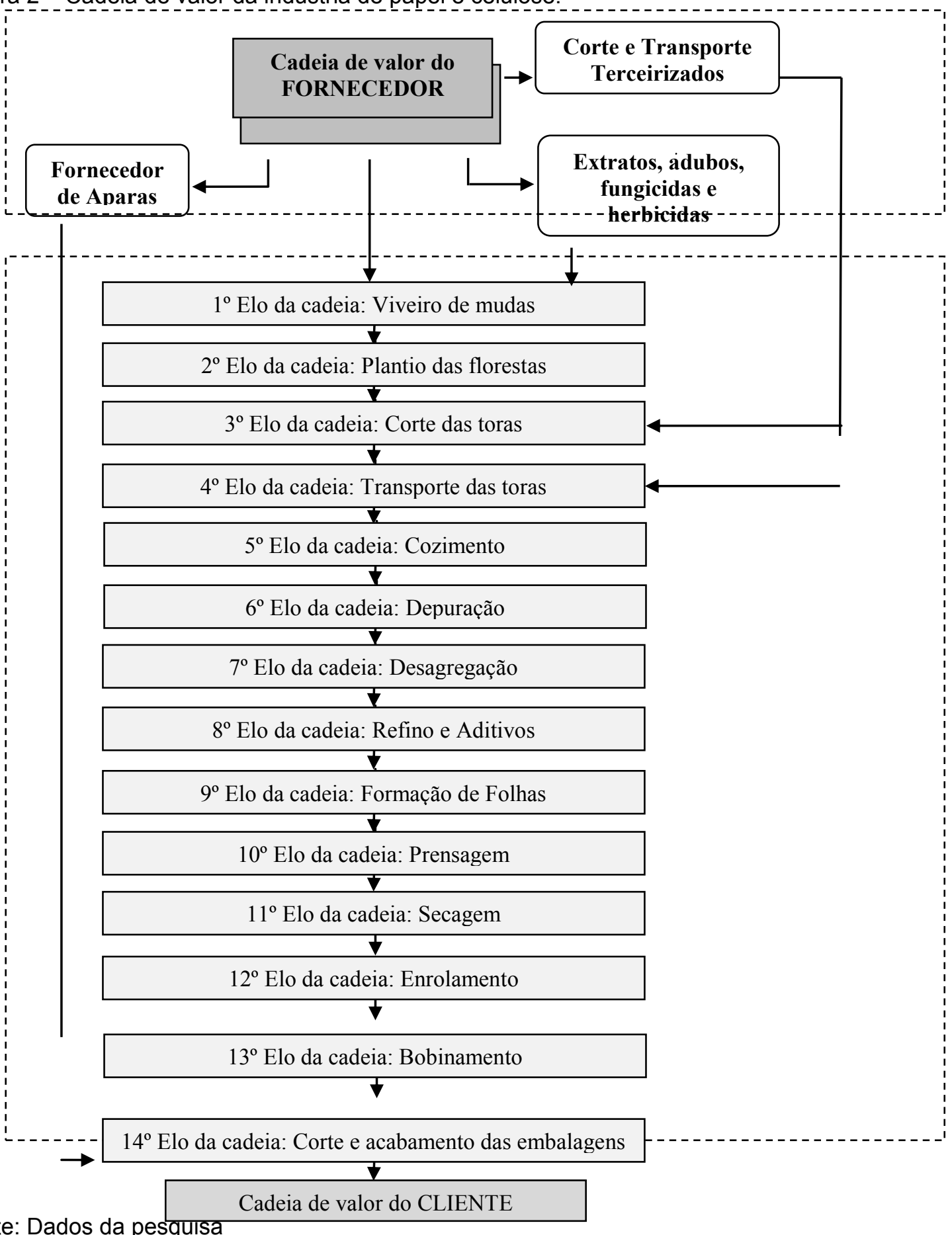

Fonte: Dados da pesquisa

Cadeia de valor do CLIENTE

Ágora: R. Divulg. Cient., v. 21, n. 1, p. 84-120, jan./jun. 2016 (ISSNe 2237-9010) 
Nota-se, pela Figura 2, a cadeia de valor global a qual a Empresa faz parte. Percebe-se que a empresa sob sua execução a maior parte dos elos da cadeia de valor, ou seja, está inserida em uma cadeia com elevado grau de verticalização, onde que a empresa é responsável desde o plantio de mudas ao desenvolvimento dos produtos diferenciados aos clientes. Além dos elos foram incluídos os fornecedores e clientes. Os fornecedores relevantes são os prestadores de serviços de corte e transporte das toras, juntamente com os fornecedores de aparas e insumos e defensivos para o plantio do pinus, sendo que nem todos tem entrada no início da cadeia. E por fim, os clientes que são os grandes compradores de todo os produtos da empresa, que por sua vez, atua no mercado focado nas necessidades dos seus clientes.

\subsection{FATORES CONTINGENCIAIS E O GERENCIAMENTO DA CADEIA DE VALOR DA EMPRESA}

A interação entre os elos da cadeia de valor na busca pela otimização de resultados operacionais e financeiros é um dos objetivos de haver um sistema integralmente verticalizado na indústria. Nessa cadeia de valor e em todas outras organizações, fatores contingências interferem e impactam na gestão. Assim, para a otimização dos resultados totais da cadeia de valor, os fatores contingências precisam ser conhecidos e gerenciados. Esses fatores podem ser internos ou externos a cada elo da cadeia de valor.

\subsubsection{Fatores Contingenciais Externos}

A literatura apresentada no referencial teórico aborda que existem algumas influências externas na gestão da cadeia de valor para o controle de custos, tais como: atitudes da concorrência (outros produtores e outras integradoras); competição por mão de obra; disponibilidade de crédito para investimento; competição por compra de insumos; tecnologia aplicada ao processo produtivo; consumo do mercado interno/externo; restrições legais, ambientais, políticas e 
econômicas do setor; atitudes políticas, sindicatos, associações, etc. e gostos e preferências dos clientes dos consumidores finais.

Foi realizada a seguinte pergunta: Qual é o posicionamento (ações) da empresa quanto à gestão de custos nas seguintes situações externas que influenciam os elos da cadeia de valor que pertence? Especificamente a Atitudes da concorrência? Pela percepção do entrevistado, a empresa por ser a terceira maior em caixas de papelão e a quarta em papel e celulose sofre negativamente com a concorrência, porém isso vem sendo minimizado, pois a empresa busca desenvolver valor agregado aos seus produtos buscando produzir produtos específicos para os seus clientes, ou seja, atuando no mercado com diferenciação dos seus produtos. Segundo o entrevistado, este posicionamento também é observado pelas demais concorrentes que possuem maior participação de mercado do que a própria companhia.

Assim, quanto à influência da concorrência a estratégia é realizar parcerias com os clientes, no caso as indústrias, quando as mesmas estão desenvolvendo um produto alimentício novo, a Empresa participa do processo elaborando a melhor embalagem possível para aquele produto. A caixa de papelão deve conter as especificações técnicas e preços compatíveis com as demandas mercadológicas dos produtos da indústria alimentícia. A elaboração de produtos específicos para as indústrias alimentícias proporcionou a fidelização do cliente, com uma parceria que permitiu a geração de maior valor agregado tanto para o cliente quanto para a própria companhia. De acordo com o entrevistado, esta estratégia foi perfeitamente executada em decorrência da companhia ter sob seu domínio a maior parte da cadeia de valor, sendo que tal estratégia aumentam os resultados da firma.

Quando foi questionado sobre qual seria o posicionamento da empresa quanto às variáveis externas referente ao controle de custos, especificamente para a concorrência de mão-de-obra, o respondente posicionou-se abordando que a empresa busca desenvolver seus colaboradores disponibilizando cursos e treinamento. Para reter seus colaboradores, a empresa oferece um plano de salários e benefícios mais consistente do que as demais empresas da região. Quando a empresa necessita de profissionais busca inicialmente promover colaboradores internos, não encontrando, busca profissionais no mercado de trabalho. Em resumo, a empresa não sofre influência significativa referente a concorrência de mão-de-obra 
nos custos de produção, entretanto, os custos mais elevados da mão-de-obra da empresa são repassados aos seus produtos da cadeia de valor que posteriormente são repassados aos clientes.

Quanto à variável externa de disponibilidade de crédito, o entrevistado mencionou que atualmente a empresa não sofre maiores dificuldades para obter recursos de capital com baixo custo. A companhia teve dificuldades de obter créditos em 2008 com a crise financeira que abalou economicamente o país, porém isso já está superado e a empresa obtém recursos financeiros de forma facilitada. Dessa forma, observa-se que o custo de capital não onera os produtos da empresa.

Quanto à compra de insumos, o entrevistado aborda que a companhia não sofre grandes influências externas no custo da cadeia de valor, pois produz $70 \%$ da matéria prima - madeira com florestas próprias, podendo controlar e estabilizar o custo de produção deste insumo. Sofre uma pequena influência externa na compra de insumos quando necessita adquirir do mercado as aparas, que é a folha ondulada que compõe a caixa de papelão, sendo que para ser fabricada, a mesma necessita de papel reciclado que teve um aumento de aproximadamente $60 \%$ no mercado. Estes aumentos de custos nem sempre são repassados ao produto final tendo a empresa que absorvê-lo. Segundo o entrevistado, nem o desenvolvimento de novos fornecedores reduz tal custo, pois não há matéria prima alternativa e o produto é muito visado pelas indústrias de caixa de papelão. Diante disso, observase a certa influência destes fornecedores, tal abordagem já foi constatada na literatura por Porter (1989) e Shank e Govindarajan (1997), que mencionavam que fornecedores não são meros entregadores de insumos, eles influenciam de forma relevante nos custos da empresa e no seu posicionamento estratégico.

Quanto às tecnologias aplicadas ao processo produtivo, o entrevistado aborda que a companhia mantém uma política de investimentos agressiva, pois as empresas que desejam permanecer no setor de papel e celulose necessitam constantemente modernizar seus parques fabris. Isso envolve novas tecnologias em todo o processo produtivo desde o desenvolvimento de novas mudas, formas de limpeza e manutenção das plantações até a industrialização da celulose em seu produto final.

Quanto ao consumo do mercado interno/externo como variável externa que interfere no custo da cadeia de valor observa-se que não há grandes alterações 
de consumo, pois a maior parte dos produtos da empresa são comercializados para indústrias nacionais que acompanham as tendências de consumo do país.

Quanto às restrições legais, ambientais, políticas e econômicas do setor é mencionado pelo entrevistado que todas são cumpridas como determina a legislação. Na área ambiental, a empresa mantém políticas de conservação do meio ambiente e tratamento dos resíduos que estão acima do que é o mínimo exigido pelas leis ambientais, tais como: a lei determina que a companhia mantenha $30 \%$ das plantações como reserva legal, sendo que a mesma mantém 50\%; a água que é utilizada no processo produtivo é devolvida a natureza com um $\mathrm{PH}$ menor do que é estabelecido por pela legislação ambiental. De acordo com o entrevistado, tal posicionamento da empresa não impacta significativamente no custo dos seus produtos.

As atividades políticas, sindicais, associações, etc. não geram impacto significativo na cadeia de valor e custo do produto final da empresa. Todos os anos ocorrem as negociações da empresa com o sindicato sobre o dissídio coletivo, sendo que esta ocorre sem conflitos entre as partes. O impacto gerado pelo dissídio sempre são repassados para os produtos finais da empresa.

Quanto à variável externa - Gostos e preferências dos clientes dos consumidores finais, o entrevistado aborda que "a empresa trabalha há alguns anos com o conceito de marketing industrial que frisa e intensifica a questão do foco do cliente, ou seja, a empresa olha para onde seu cliente está olhando". Dessa forma, esta variável ambiental possui significativa influência nos elos da cadeia de valor da empresa, mesmo não tendo grande volatilidade.

Nesta análise das variáveis contingenciais constata-se que elas existem na cadeia de valor da empresa e influenciam nas atividades de gestão de custos da empresa, demonstrando que o gestor precisa coletar e analisar as informações do seu ambiente externo. Esses resultados confirmam os resultados encontrados por Espejo (2008), Junqueira (2010) e Fagundes et al. (2010).

\subsubsection{Fatores Contingenciais Internos}

Foram analisadas as influências dos seguintes fatores internos contingenciais no gerenciamento e controle de custos da cadeia de valor da empresa: tecnologia, 
estrutura, estratégia e porte. Conforme comentários e percepção do entrevistado e colaborador interno da empresa quanto aos fatores, seguem os detalhes.

\subsubsection{Tecnologia}

Inicialmente solicitou-se a percepção do entrevistado quanto à tecnologia utilizada em cada elo da cadeia de valor, ou seja, se a mesma é adequada. Segundo a opinião do mesmo, a tecnologia é adequada e a empresa necessita de uma atualização tecnológica constante para que a empresa não perca espaço no mercado. Para fomentar isso, a companhia possui duas políticas de investimentos, a primeira é em investimentos correntes para modernização tecnológica de linhas de produção já existentes e a segunda em investimentos estratégicos realizados na aquisição de novas máquinas (linhas de produção) ou plantas fabris. Portanto, observa-se que a variável interna - tecnologia implica na gestão de custos da cadeia de valor sendo ela considerada adequada, pois são realizados investimentos constantes para manter a estratégia competitiva adotada pela empresa repassada aos produtos comercializados.

Quanto ao posicionamento da empresa referente à influência que ocorre na tecnologia de pesquisa e desenvolvimento de produtos em cada elo da cadeia de valor, quanto ao resultado operacional e financeiro global, o respondente menciona que a empresa possui várias áreas de Pesquisa e Desenvolvimento (P\&D) que foca seus esforços no desenvolvimento de produto, sendo que a inovação hoje é uma das peças chaves da maior importância dentro da empresa, sendo que a mesma é destaque em inovação. Já para a variável tecnologia de equipamentos/instalações o respondente aborda que os equipamentos são avaliados constantemente e atualizados. Para a variável interna de tecnologia da automação produtiva, a companhia busca constantemente a atualização tecnológica como uma de suas políticas internas.

E por fim, quanto a variável de tecnologia de transporte/logística, a companhia realiza estudos frequentes para melhorar a logística de entrega, geralmente em parceria com os próprios clientes. Pela percepção do respondente, a inovação tecnológica em produtos, processo, etc. de cada elo da cadeia de valor constituem uma peça chave para a empresa manter seu posicionamento estratégico e o 
controle de custos dentro do mesmo. A postura da empresa em realizar estudos frequentes revela sua preocupação em ajustar o sistema de controle gerencial com as variáveis contingenciais, que segundo Espejo (2008), muda constantemente dependendo das novas condições do ambiente da empresa.

\subsubsection{Estrutura}

Quanto à estrutura, foi questionado sobre qual seria a influência da empresa sobre os fornecedores, especificamente referente às matérias primas fornecida e a empresa, por considerar a sustentabilidade uma fonte de inspiração, busca criar este conceito também em seus fornecedores, os mesmos são acompanhados pela área de suprimentos a fim de que certas ações ocorram. Na área florestal, o certificado do FSC acaba filtrando automaticamente fornecedores que consigam manter a sustentabilidade. Já a influência da empresa na comercialização ocorre, pois as vendas são desenvolvidas por equipes internas, treinadas que buscam auxiliar os clientes a alcançarem seus objetivos mercadológicos e de vendas. Dessa forma, a existência da companhia nesta cadeia de valor exerce certamente influência nas ações dos fornecedores e de seus clientes, impondo-lhes nova estrutura de custos em decorrência disso.

Referente ao recebimento de considerações, sugestões sobre o fluxo de produção dos demais gestores da cadeia interna e externa, o entrevistado aborda que a empresa possui um programa de captação de ideias institucionalizado: IDEIAS DE VALOR. Esse programa faz parte da governança participativa onde cada colaborador é parte integrante, sempre tendo como fonte o planejamento estratégico. Todas as ideias sugeridas são analisadas por uma metodologia desenvolvida pela própria empresa, em seguida as sugestões são repassadas para a diretoria para a possível execução. Segundo o entrevistado muitas ideias foram aproveitadas e postas em prática pela empresa, e ainda, a companhia possui dois projetos junto ao FINEP de aproximadamente 25 milhões que foram ideias capturadas pelo programa. Portanto, observa-se que este programa também proporciona certa influência para a gestão de custos da cadeia de valor da companhia. 
Foi questionado ao respondente sobre qual seria a influência no resultado global da estrutura física e operacional utilizada pelos elos da cadeia de valor da empresa e como era exercida a gestão de custos para aperfeiçoar os resultados dessa influência, o respondente mencionou que a gestão de custos é feita em cada etapa ou cada elo da cadeia, sendo que é balizada pelo orçamento empresarial que surge baseado no planejamento estratégico.

\subsubsection{Estratégia}

Quanto à variável interna - estratégia, questionou-se sobre quais seriam os principais pontos fortes e fracos da cadeia de valor que a empresa está inserida, o respondente mencionou que o ponto forte mais relevante são os valores da empresa bem definidos, que, por exemplo, norteiam as ações do departamento de vendas, ou seja, cada produto tem um determinado preço e a empresa não negocia abaixo disso. Como ponto fraco, o respondente não encontrou algo relevante e significativo para mencionar. A cadeia de valor é parte integrante do mapa e dos indicadores estratégicos analisados mensalmente. Portanto, observa-se que a empresa faz uso do seu amplo domínio sobre a cadeia de valor para gerenciar seus preços finais com os clientes.

Foi questionado sobre qual seria o posicionamento da empresa na cadeia de valor quanto à: ênfase na busca da alta qualidade do produto frente ao concorrente; atendimento ao cliente do produto frente à concorrência; desenvolvimento de características únicas do produto; buscar uma imagem melhor dos produtos do que a concorrência; investir mais em pesquisa e desenvolvimento do que o concorrente; buscar preço de venda menor do que o concorrente. De modo geral, o respondente abordou que a busca por todos estes itens não é balizada pela concorrência e sim pelo foco do cliente, que por sua vez, são clientes que possuem grande fatia dos mercados que atuam com preços maiores devido à qualidade dos seus produtos.

Questionou-se qual seria a influência da empresa nas práticas de gestão de custos aplicadas nos elos da cadeia de valor. O respondente mencionou que a prática acaba se tornando cultural e institucionalizando-se nas ações dos colaboradores, sendo que o entrevistado mencionou que há alguns anos atrás a empresa realizou um estudo de terceirização de alguns elos produtivos, tais como: 
desenvolvimento de mudas, plantio, manutenção das florestas e chegou a conclusão que não era viável financeiramente e poderia perder o controle da qualidade do processo produtivo, dessa forma manteve-se a primarização. Os serviços de corte da floresta e transporte da madeira são terceirizados atualmente e foi uma medida tomada há muitos anos atrás quando foi observada a redução de custos que tal medida proporcionava. Dessa forma, a empresa analisa constantemente os custos da cadeia de valor.

Abordou-se também, sobre quais seriam as principais ameaças $\mathrm{e}$ oportunidades para a empresa com relação à sua cadeia de valor. O respondente aborda que oportunidades sempre existem, mas a principal é balizada pela missão da empresa e sempre estará ligada tanto ao investidor quanto ao cliente. Ameaças também existem, mas são controladas e medidas pelos comitês internos e pelas práticas de parcerias. Também foi questionado se a variação cambial oferecia algum tipo de ameaça ao negócio da empresa, o entrevistado respondeu que não, pois qualquer desvalorização do dólar fomentaria positivamente a venda dos seus clientes que acabariam comprando mais caixas de papelão e se houvesse a valorização do dólar estas mesmas empresas acabariam colocando sua produção no mercado interno e não deixariam de comprar embalagens. Segundo o respondente, esta é uma condição mercadológica específica, pois a Empresa possui clientes líderes de mercado na área alimentícia e frigorífica. É importante mencionar também que a companhia exporta, com isso é realizado um hedge natural para o pagamento das dívidas em dólares. Segundo o entrevistado, a grande ameaça hoje é o preço das aparas, que já foi abordado anteriormente, sendo que seu preço é regulado pela oferta e procura do mercado, e que no último ano aumentou em torno de $60 \%$, quanto a esta ameaça externa não há nada que possa ser feito para reduzir o seu custo. Dessa forma, a única ameaça observada para a empresa entre a compra de insumos e venda dos seus produtos finais é a aquisição de uma matériaprima do mercado nacional que apresenta um custo de aquisição crescente nos últimos anos.

Indagou-se sobre quais seriam os controles de qualidade do produto final exigidos pela empresa dos seus fornecedores. O respondente abordou que são feitos vários testes como de umidade e resistência na hora da entrega na fábrica, ocorrendo inconsistências, há a negociação imediata de descontos ou devoluções. 
Por fim, a esta variável, foi solicitada a opinião do ponto de vista do respondente sobre qual seria a fase (ou elo) que mais necessita de controles para obter eficiência. O respondente abordou que é a fase produtiva, ou os elos da cadeia de valor correspondentes ao processo produtivo da empresa, pois é neste momento que você vai transformar a sua relação com o cliente em produto e consequentemente em resultado concreto vinculando o diferencial da companhia.

\subsubsection{Porte}

Abordando a variável interna - porte, questionou-se também sobre qual seria a influência da quantidade de produção por elo na eficiência do resultado global da empresa. O respondente mencionou que o volume é balizador de custo e consequentemente gera impactos positivos no resultado. Questionou-se também se ocorria à negociação de custos de matéria prima com os fornecedores e como ocorria. O respondente mencionou que era desenvolvido dentro dos critérios préestabelecidos pela área de suprimentos, sempre com aprovação da diretoria.

\section{CONCLUSÕES}

A presente pesquisa teve como objetivo identificar como os fatores contingenciais impactam o gerenciamento da cadeia de valor de uma indústria de papel e celulose do estado de Santa Catarina. Desenvolveu-se pesquisa qualitativa com aplicação de entrevista semiestruturada, utilizando questões que envolveram as variáveis contingenciais externas e internas, abordadas no referencial teórico do estudo, que visam a gestão de custos da cadeia de valor.

A empresa definida para o estudo foi que a Empresa de papel e celulose atua no ramo desde 1941, é uma companhia aberta que apresenta um melhor nível corporativo, e também, está entre as 4 maiores empresas de embalagens de papel e celulose do Brasil e realiza parceria no desenvolvimento de embalagens com as maiores companhias de alimentos do setor frigorífico brasileiro.

A cadeia de valor da empresa foi mapeada e verificou-se que a empresa está em uma cadeia altamente verticalizada, porque possui a maioria dos elos da cadeia de valor sob seu controle administrativo direto. A área de custos da empresa 
realiza análises constantes sobre os custos da cadeia de valor por meio de estudos de viabilidade financeira. Os elos da cadeia de valor interna ou processos produtivos da empresa necessitam de constantes investimentos para que seja mantida a qualidade e baixo custo dos produtos, sendo que a empresa atua no mercado focando as necessidades dos clientes, não competindo com o menor preço.

Foram analisadas as variáveis externas : atitudes da concorrência; competição por mão de obra; disponibilidade de crédito para investimento; competição por compra de insumos; tecnologia aplicada ao processo produtivo; consumo do mercado interno/externo; restrições legais, ambientais, políticas e econômicas do setor; atitudes políticas, sindicatos, associações, etc. e gostos e preferências dos clientes dos consumidores finais.

Quanto à atitude da concorrência a empresa não sofre tanto, pois atua no mercado com uma forte parceria com seus clientes. Referente à competição de mãode-obra, a companhia não sofre tanto por investir em cursos e treinamentos e busca disponibilizar para os seus colaboradores um plano de benefícios melhor do que as demais empresas da região.

A respeito da disponibilidade de crédito, segundo o entrevistado, a empresa não enfrenta dificuldades para adquirir novas linhas de financiamento. Entretanto, foi observada na variável competição por compra de insumo a elevação do custo das aparas, que é uma matéria-prima adquirida de fornecedores nacionais, sendo que o risco observado é a redução dos ganhos da companhia na cadeia de valor. Diante desta variável, verifica-se certa dependência da empresa frente aos fornecedores, Porter (1989) e Shank e Govindarajan (1997), já abordavam sobre isso mencionando que os fornecedores exercem influência nos custos das empresas e no seu posicionamento estratégico.

Quanto a variável tecnologia aplicada ao processo produtivo, a empresa possui uma política de investimento e está conseguindo executá-la perfeitamente pela boa disponibilidade de crédito que possui. Sobre a variável consumo do mercado interno/externo, a empresa acaba acompanhando as variações dos mercados dos seus clientes parceiros, que não oscilam tanto. Referente às restrições; legais, ambientais, políticas e econômicas do setor, atitudes políticas, sindicatos, associações, etc., a empresa atende a todas as imposições legais exigidas pelas entidades e reserva mais atenção às exigências ambientais e adota 
medidas acima do que é o mínimo exigido por lei. Quanto aos gostos e preferências dos consumidores finais, a própria postura de atuação da empresa focada nas necessidades dos clientes responde este requisito.

Foram analisadas as seguintes variáveis internas: tecnologia, estrutura, estratégia e porte. Conforme a percepção do entrevistado, a variável tecnologia influencia em todos os processos produtivos da empresa, pois a ausência destes investimentos retira gradativamente a empresa do mercado devido a redução da qualidade e lucratividade dos seus produtos. Quanto a variável estrutura, foi mencionado que a empresa influenciou alguns fornecedores para a adoção de algumas medidas benéficas de desenvolvimento corporativo, sendo que isso foi observado quando a Companhia aderiu ao FSC que exigia que os fornecedores da empresa fossem sustentáveis também. A empresa também possui um programa institucionalizado para captar ideias dos colaboradores, que por sua vez, já colheu ideias muito interessantes que foram postas em prática.

Referente a variável estratégia, a empresa atua no mercado com uma postura focada nas necessidades do cliente, entretanto, está sendo influenciada pelos aumentos constantes das aparas, quem influenciam seus resultados. Segundo o entrevistado, os custos no processo produtivo e consequentemente na cadeia de valor são avaliados constantemente. E por último, o variável porte, que foi apresentada como uma condição importante para a determinação dos custos, ou seja, o tamanho do parque fabril determina a estrutura de custos da organização, e também pode determinar outro nível de negociação com fornecedores.

A contribuição deste estudo está na identificação de variáveis internas e externas que representem oportunidades ou ameaças para a gestão de custos e em condicionantes internos ou externos que possam aumentar ou reduzir os custos do processo produtivo ou da cadeia de valor. A análise da cadeia de valor juntamente com o posicionamento estratégico pode proporcionar relevante contribuição para o controle e redução de custos da organização. Como conclusão geral, depois do mapeamento da cadeia de valor, constatou-se que as variáveis contingenciais exercem influências no controle de custos da indústria de celulose. Esses resultados estão de acordo com os resultados encontrados por Espejo (2008), Junqueira (2010) e Fagundes et al. (2010). 
Como sugestão para futuras pesquisas indica-se a realização de pesquisas que avaliem a influência das variáveis contingenciais na gestão de custos da cadeia de valor em outras empresas do setor de papel e celulose, tais como as que industrializem celulose para a fabricação de papel para imprensa, papel para imprimir e escrever, papel para embalagem, papéis sanitários, papel para cartão e cartolina e papeis especiais. Com os resultados destes estudos poderia ser realizado um comparativo dos segmentos do setor econômico.

\section{REFERÊNCIAS}

AGUIAR, A. B.; ROCHA, W. Uma análise da complementaridade entre gestão interorganizacional de custos e open-book accounting. 7. Congresso USP de Controladoria e Contabilidade. São Paulo, 2007.

ANAND, M. A review of research on the theory \& practice of cost management. South Asian Journal of Management. v. 11, n. 1, p. 59-98, jan./mar, 2004.

ANDERSON, S.W. Managing costs and cost structure throughout the value chain: research on strategic cost management. In Chapman, C.; Hopwood, A.; Shields, M. (editor) Handbook of Management Accounting Research, v. 2. Oxford: Elsevier, 2006. Disponível em: <http://ssrn.com/abstract=869070> Acesso em: 17 mar. 2008.

ANTONHY, R. N.; GOVINDARAJAN, V. Sistemas de controle gerencial. São Paulo: Atlas, 2002.

ASSOCIAÇÃO BRASILEIRA DE CELULOSE E PAPEL (BRACELPA). Dados do Setor, jul. 2012. Disponível em:

<http://www.bracelpa.org.br/bra2/sites/default/files/estatisticas/booklet.pdf>. Acesso em: 08 dez. 2013.

BACIC, M. J. Escopo da gestão estratégica de custos em face das noções de competitividade e de estratégia empresarial. Congresso Brasileiro de Gestão Estratégica de Custos. 1. São Leopoldo, Unisinos, 1994.

BAER, W. A economia brasileira. 3. ed. São Paulo: Nobel, 2009.

BOMFIM, G. M. Gerenciamento de resultados em cursos de pós graduação latu senso através da metodologia do custeio alvo. 2006. Dissertação (Mestrado em Controladoria e Contabilidade) - Faculdade de Economia, Administração e Contabilidade da Universidade de São Paulo. São Paulo, 2006.

BORGES, A. P.; ROSA, F.; ENSSLIN, S. R. Evidenciação voluntária das práticas ambientais: um estudo nas grandes empresas brasileiras de papel e celulose.

Produção On Line, v. 20, n. 3, p. 404-417, 2010. 
BOWERSOX, D. J.; CLOSS, D. J. Logistical management: the integrated supply chain process. New York: McGraw-Hill, 730 p., 1996.

BRITO, R.S.; GARCIA, S. MORGAN, B. F. Custeio alvo: utilização do sistema de gerenciamento de lucro pelos fabricantes de veículos automotores com indústria no Brasil. Revista de Contabilidade e Organizações, v. 2, n.2, p. 71-86, 2008.

CAMACHO, R. R.; ROCHA, W. Custeio alvo: uma abordagem conceitual e utilitarista. Enfoque: Reflexão Contábil, v. 26, n. 3, p. 28-38, 2007.

CARVALHO, R. C. Método para identificação de custos ambientais na cadeia produtiva de papel e celulose. 2001. Dissertação (Mestrado em Engenharia da Produção) - Programa de Pós-Graduação em Engenharia da Produção.

Florianópolis, UFSC, 2001.

CHENHALL, R. H. Management control systems design within its organizational context: findings from contingency-based research and directions for the future.

Accounting, Organization and Society, v. 28, n. 2, p. 127-168, 2003.

COOPER, R.; SLAGMULDER, R. What is strategic cost management? Managent Accounting. ABI/INFORM Global, v. 79, n. 4, p. 14 -16, 1998.

COVALESKI, M.A.; DIRSMITH, M.W.; SAMUEL, S. Managerial accounting research: the contributions of organizational and sociological theories. Journal of Management Accounting Research, v. 8, p. 1-36, 1996.

DA SILVA, C. L.; KOPITTKE, B.H. Simulações e cenários a partir da cadeia de valor: uma aplicação na indústria de celulose. Revista FAE, v.5, n.1, p.43-59, jan./abr. 2002.

DEKKER, H.; SMIDT, Peter. A survey of the adoption and use of target costing in Dutch firms. International Journal of Production Economics, v. 84, n. 3, p. 293305, 2003.

DRAZIN, R.; VAN DE VEN, A.H. Alternative forms of fit in contingency theory. Administrative science quarterly, p. 514-539, 1985.

EL-KELETY, I. A. E. M. A. E. Towards a conceptual framework for strategic cost management: the concept, objective, and instruments. 2006. $556 \mathrm{f}$. Dissertação. Chemnitz University of Technology, Chemnitz, 2006. Disponível em: http://archiv.tuchemnitz.de/pub/2006/0115/index.html Acesso em: 21 de maio de 2008.

ELLRAM, L. M.; SIFERD, S. P. Purchasing: the cornestone of the total cost of ownership. Journal of Business Logistics, v. 14, p. 163-185, 1993.

. The implementation of target costing in the United States: theory versus practice. Journal of Supply Chain Managemet, v. 42, p. 13-26, 2006. 
ESPEJO, M. M. S. B. Perfil dos atributos do sistema orçamentário sob a perspectiva contingencial: uma abordagem multivariada. $2008.216 \mathrm{f}$. Tese (Doutorado em Ciências Contábeis) - Faculdade de Economia, Administração e Contabilidade da Universidade de São Paulo, São Paulo, 2008.

FAGUNDES, J. A. et al. Estrutura organizacional e gestão sob a ótica da teoria da contingência. Gestão e Regionalidade. v. 26. n. 78, p. 52-63, 2010.

FARIA, A.C.; COSTA, M. F. G. Gestão de custos logísticos. São Paulo: Atlas, 2005.

FISHER, J. G. Contingency-based research on management control systems: categorization by level of complexity. Journal of Accounting Literature. v.14, p. 24-53, 1995.

FREZATTI, F. et al. Antecedentes da definição do design do sistema de controle gerencial: evidências empíricas nas empresas brasileiras. Brazilian Business Review, v. 9, n. 1, p. 134-155, 2012.

FU, Y. Strategic cost management in e-supply chain. Asian-Pacific Management Accounting Journal, v. 2, p. 89-119, 2007.

GALLON, A.; GRUNOW, A.; BEUREN, I.M. Logística integrada de produção e industrialização de aves: o caso da Seara Alimentos S.A. ABCustos Associação Brasileira de Custos, v. 4, n. 1, jan./abr. 2009.

HANSEN, D. R.; MOWEN, M. M.; Gestão de custos: contabilidade e controle. São Paulo: Pioneira, 2001.

HOFER, E.; DE SOUZA, J. A.; ROBLES JUNIOR, A. Gestão estratégica de custos na cadeia de valor do leite e derivados. Custos e@ gronegócio on line. v, 3, maio, 2007.

HORNGREN, C. T.; FOSTER, G.; DATAR, S. M. Contabilidade de custos. 9. ed. Rio de Janeiro: LTC, 2000.

JORDÃO, R. V. D. ; DE SOUZA, A.A. Aquisição de empresas como fator de mudança no sistema de controle gerencial: uma análise estratégica sob a perspectiva da teoria contingencial. Revista Universo Contábil, v.9, n.3, p. 75-103, jul./set., 2013.

JORDÃO, R. V. D.; SOUZA, A. A. Efeitos da cultura corporativa no sistema de controle gerencial pós-aquisição: um estudo de sucesso numa empresa brasileira. Revista de Gestão, v. 19, n. 1, p. 55-71, 2012.

JUNQUEIRA, E. R. Perfil do sistema de controle gerencial sob a perspectiva da teoria da contingência. 2010. 147 f. Tese (Doutorado em Ciências Contábeis) Faculdade de Economia, Administração e Contabilidade da Universidade de São Paulo, São Paulo, 2010. 
LACOMBE, B. M. B.; CHU, R. A. Políticas e práticas de gestão de pessoas: as abordagens estratégica e institucional. Revista de Administração de Empresas, v. 48, n.1, p. 25-35, 2008.

LOCKAMY III, A. A constraint-based framework for estrategic cost management. Industrial Management + Data Systems. Wembley, v. 103, n. 8/9, p. 591-599, 2003.

LOPES, C. R. A. Análise da indústria de papel e celulose no Brasil. 1998. Dissertação (Mestrado) - Instituto de Pós-graduação e Pesquisa em Administração, UFRJ, Rio de Janeiro. 1998.

LORANDI, J. A.; BORNIA, A. C. Metodologia do custeio-alvo canalizado com o do QFD (quality function deployment). Revista de Contabilidade do Mestrado em Ciências Contábeis da UERJ, v. 16, n. 2, p. 96-115, 2011.

LUFT, J.; SHIELDS, M. D. Mapping management accounting: graphics and guidelines for theory-consistent empirical research. Accounting, Organizations and Society, v. 28, n. 2/3, p.169-249, 2003.

MARQUES, K. C. M. Custeio alvo à luz da teoria da contingência e da nova sociologia institucional: estudo de caso sobre sua adoção, implementação e uso. 2012. Tese (Doutorado em Controladoria e Contabilidade: Contabilidade) Faculdade de Economia, Administração e Contabilidade, Universidade de São Paulo, São Paulo, 2012.

MOLINARI, S.K.R; GUERREIRO, R. Teoria da contingência e contabilidade gerencial: um estudo de caso sobre o processo de mudança na controladoria do Banco do Brasil. In: Congresso USP de Controladoria e Contabilidade. 2004.

MONDEN, Y. Sistemas de redução de custos: custo-alvo e custo kaizen. Bookman, 1999.

NAKAGAWA, M. ABC custeio baseado em atividades. Atlas, 1994.

PORTER, M. Vantagem competitiva: criando e sustentando um desempenho superior. 24. ed. Rio de Janeiro: Campus, 1989.

ROCHA, M. M. Integração vertical e incerteza. 2002. 201 f. Tese (Doutorado em Economia) - Faculdade de Economia, Administração e Contabilidade da Universidade de São Paulo, São Paulo, 2002.

ROCHA, W. Contribuição ao estudo de um modelo conceitual de sistema de informação de gestão estratégica. 1999. Tese de Doutorado. Faculdade de Economia, Administração e Contabilidade da Universidade de São Paulo, 1999.

ROCHA, W; BORINELLI, M. L. Análise estratégica de cadeia de valor: um estudo exploratório do segmento indústria-varejo. Revista Contemporânea de Contabilidade, v. 4, n.7, p.145-165, 2007. 
ROCHA, Welington; MARTINS, Eric. Custeio-Alvo. Revista Brasileira de Custos, v. 1, n. 1, p. 83-94, maio/ago. 1999.

SHANK, J. K.; GOVINDARAJAN, V. A revolução dos custos: como reinventar e redefinir sua estratégia de custos para vencer em mercados crescentemente competitivos. 6 ed. Rio de Janeiro: Campus, 1997.

SHANK, J.K. Gestão estratégica de custos: a nova ferramenta para a vantagem competitiva. Rio de Janeiro: Campus, 1995.

SILVA, M. Z. da; SCARPIN, J. E.; BARP, A. E.; DIAS, D. R. Determinantes contingenciais que contribuem para efetividade do sistema de custeio em hospitais: um estudo de caso em um hospital do Vale do Itajaí-SC. In: CONTECSI Congresso Internacional de Gestão da Tecnologia e Sistemas de Informação, 9., 2012. Anais..., Faculdade de Economia, Administração e Contabilidade, Universidade de São Paulo, 2012.

SOUZA, B. C.; ROCHA, W. Fatores condicionantes da gestão de custos interorganizacionais. 8. Congresso USP de Controladoria e Contabilidade. São Paulo, 2008.

WATERHOUSE, J. H.; TIESSEN, P. A. A Contingency Framework for Management Accounting Systems Research. Accounting, Organizations and Society, v. 3, n. 1, p. 65-76, 1978.

WOOD JR, T.; P CALDAS, M. Empresas brasileiras e o desafio da competitividade. Revista de Administração de Empresas, v. 47, n. 3, p. 1-13, 2007.

WOODWARD, J. Industrial organizations: theory and practice. London: Oxford University Press, 1965.

WRUBEL, F.; DIEHL, C. A.; TOIGO, L. A.; OTT, E. Uma proposta para a validação de categorias sobre gestão estratégica de custos. Revista Brasileira de Gestão de Negócios, v. 13, n. 40, p. 332-348, 2011.

WRUBEL, F. Informações sobre gestão estratégica de custos divulgadas por companhias abertas brasileiras. 2009. 145 f. Dissertação (Mestrado em Ciências Contábeis) - Curso de Pós-Graduação em Ciências Contábeis, Universidade do Vale do Rio dos Sinos, São Leopoldo, 2009.

Artigo recebido em: 21/03/2016

Artigo aprovado em: 15/07/2016 